\title{
Transport planning in Dublin and Edinburgh
}

\author{
W.]. Whitney, BA, BAI and M. M. O'Mahony, BE, DPhil
}

Abstract: Dublin and Edinburgh are cities of broadly comparable size, form, history and function. Both face similar transport and related problems. In the mid-to-late twentieth century, their policies in these areas have been similar in some respects but differed markedly in others. This paper establishes similarities in form and function between the cities and outlines and reviews the past four decades or so of transport planning in both cases. Notable areas of contrast are identified and are reviewed in greater depth, special attention being given to areas where Edinburgh's experience relates to current debates in Dublin. The principal areas examined include the comparison between light rail transit (LRT) and busways, underground operation of LRT in city centres, the structure of public consultation processes, the differences between strategic studies recommending a single strategy and those offering a choice, and road pricing as a restraint strategy. Finally, conclusions are drawn from this examination, particular attention being given to areas where Edinburgh's experience might be of interest to Dublin.

Keywords: transport planning

\section{Introduction}

1. Dublin currently suffers severe transport related problems including congestion, air pollution and inadequate public transport. Although they have existed to some extent for many years, they have been greatly exacerbated by Ireland's recent economic growth. These problems and their possible solutions (e.g. traffic calming, light rail transit (LRT), bus priority, road pricing) are increasingly the subject of heated political and media debate. Reference is commonly made to the success of other 'comparable'-particularly Continental European- cities in tackling such problems.

2. It was considered that something might be learnt by examining the policies pursued in a closely comparable UK city. However, most such cities differ significantly from Dublin in areas other than size and the broad thrust of their transport planning processes. For example, functions differ greatly between Dublin, a relatively non-industrialized capital city, and typical British conurbations whose development tended to be industrially based. Urban form and the nature and degree of constraints tend also to vary. Taking all things into account (and with some prior knowledge of major areas of contrast between the cities' transport planning activities) a comparison between Edinburgh and Dublin was considered the most useful ${ }^{1}$.

3. As both are essentially capital cities rather than major industrial centres like many UK cities of comparable size, Dublin and Edinburgh are very broadly similar in function. Population, on a city, metropolitan area or regional basis, lies within the same range. Urban structure is similar in many respects, as are the consequent constraints on transport. These areas of similarity are considered in detail at a later stage.

4. As will be seen, the general histories of latter-day transport planning in Dublin and Edinburgh follow a similar path. This is partly a consequence of cultural similarities and 'best practice', but close 
resemblances in form, function and consequent problems between the cities emerge from the comparison.

5. The important transport issues over the past five to ten years in both cities have been similar. In the face of increasing traffic congestion and land-use pressures, a similar range of solutions has developed, through strategic studies, lobbying and political decisions. Unfortunately, solutions have often introduced yet further problems, hindering their implementation. Despite the similarities, contrasts remain in the nature of the solutions (e.g. in the design of LRT systems and in attitudes to road pricing). Many of these relate to areas of controversy in Dublin; hence, they are particularly worthy of examination.

\section{The two cities}

Situation

6. Dublin and Edinburgh are coastal cities, Dublin being located on the east coast of Ireland and Edinburgh on the southern shore of the Firth of Forth. Both are additionally confined by mountains. In Dublin, the Dublin Wicklow range is located south of the city, stretching from the Central Plain to the Irish Sea and curtailing southward expansion in addition to acting as a barrier to movement. Edinburgh's Pentland Hills run in an east- west direction, again south of the city, roughly parallel to the coast. Airport locations (north of Dublin, west of Edinburgh) further constrain expansion. The cities are foci for various long distance transport modes.

Population, economy and history

7. In 1996, the (administrative) city of Dublin had a population of 480 996; the city and county of Dublin combined had 1025304 . $^{2}$ By comparison, the 1991 population of Edinburgh city was 418 914 and that of the then Lothian Region was $710000 .{ }^{3}$ For the purposes of the work leading to this paper, the population figures considered most important were those for the built-up area (quoted in 1991 as approximately 900000 in Dublin and about 600 000, for a similar geographical area, in Edinburgh) and the wider region (approximately 1.2 -1.3 million in both cases, depending on the definition of the Edinburgh region).

8. Dublin's dominance, over both region and country, however, is more marked than Edinburgh's, due to various factors including Ireland's more dispersed population and the presence of other major centres (e.g. Glasgow) in southern Scotland. Population densities are similar overall; in Edinburgh's case, the city's high proportion of open space and low-density private developments counteract the very high density of some social housing. ${ }^{4}$ Densities along LRT and bus corridors are presented in Table 1.

9. Economic activity in both cities is dominated by service activities including education, transport, administration, finance and the professions. Manufacturing is generally light in nature. Employment remains largely concentrated in the central business districts (CBDs), but peripheral locations with good road access are expanding rapidly. 
10. Both Dublin and Edinburgh are medieval (ninth to tenth century) in origin. The original centres, after considerable expansion, gave way in the Georgian era to entirely new residential developments that have since evolved into the present-day CBDs. Nineteenth century railway and tramway construction saw extensive development of new inner suburbs and outer commuter towns. Growth of outer suburbs, coupled with improved planning measures, such as green belts, followed in the mid-to-late twentieth century.

Structure of land use and transport networks

11. Dublin and Edinburgh possess relatively well-defined inner-city areas. Dublin's inner city is bordered by the Royal and Grand Canals whereas, in Edinburgh, features such as the Meadows and Holyrood Park provide the boundaries. In each, a CBD lies at the core, surrounded by office, institutional and residential land use. From the city centre, (generally) progressively younger residential areas extend to the urban area's outer fringe. In Dublin's case, a significant proportion of the outer suburban population is accounted for by the 'western new towns' (Blanchardstown, LucanClondalkin and Tallaght) situated west of the outer C-ring motorway (M50). Industry, office parks (e .g. Naas Road area in Dublin, South Gyle in Edinburgh) and out-of-town shopping centres (e.g. Blanchardstown and Tallaght in Dublin, Gyle and Kinnaird Park in Edinburgh) are located at key points on the road network, particularly the outer rings (M50 and A720).

Table 1. Infuences/constraints on transport system development

\begin{tabular}{|c|c|c|c|c|c|c|}
\hline \multirow[t]{2}{*}{ Transport } & \multicolumn{2}{|c|}{ Land use } & \multicolumn{2}{|c|}{ Technical } & \multicolumn{2}{|c|}{ Socio-economic } \\
\hline & $\begin{array}{c}\text { Dublin: } \\
\text { Corridor residential } \\
\text { density } \\
\text { (persons } / \mathrm{km}^{2} \text { ) }\end{array}$ & $\begin{array}{c}\text { Edinburgh: } \\
\text { Corridor residential } \\
\text { density } \\
\text { (persons } / \mathrm{km}^{2} \text { ) }\end{array}$ & Dublin & Edinburgh & Dublin & Edinburgh \\
\hline LRT & $1500-9500^{17}$ & $2500-10000^{5}$ & $\begin{array}{l}\text { Trafic } \\
\text { management } \\
\text { difficulties in } \\
\text { some central } \\
\text { areas }\end{array}$ & $\begin{array}{l}\text { Physical } \\
\text { constraints on } \\
\text { priority routes; } \\
\text { presence of disused } \\
\text { tunnel over portion } \\
\text { of alignment }\end{array}$ & $\begin{array}{l}\text { Significant role in } \\
\text { inner city } \\
\text { regeneration: } \\
\text { eventually to serve } \\
\text { many suburban } \\
\text { areas of multiple } \\
\text { deprisation. Would } \\
\text { serve major } \\
\text { peripheral housing } \\
\text { zones (e.g. Tallaght) }\end{array}$ & $\begin{array}{l}\text { Would serve most } \\
\text { areas of multiple } \\
\text { deprivation; would } \\
\text { tink most main } \\
\text { population } \\
\text { concentrations with } \\
\text { both central and } \\
\text { peripheral } \\
\text { employment zones }\end{array}$ \\
\hline Bus & $1500-9500^{17}$ & $\begin{array}{l}2500-5000 \\
\text { (general) }^{5} \\
2500-10000 \\
\text { (CERT corridor) }^{5}\end{array}$ & $\begin{array}{l}\text { Capacity/ } \\
\text { enrironmental } \\
\text { problems }\end{array}$ & $\begin{array}{l}\text { Cheaper and easier } \\
\text { to implement than } \\
\text { rail: technical } \\
\text { problems with some } \\
\text { routes }\end{array}$ & $\begin{array}{l}\text { Quality Bus to be } \\
\text { implemented on all } \\
\text { major corridors } \\
\text { other than those to } \\
\text { be served by LRT }\end{array}$ & $\begin{array}{l}\text { CERT busway } \\
\text { would serve some } \\
\text { areas of multiple } \\
\text { deprivation and link } \\
\text { CBD with main } \\
\text { peripheral } \\
\text { employment zones }\end{array}$ \\
\hline
\end{tabular}

12. Highway networks are heavily biased towards radial links focused on the city centres. These are of relatively limited capacity owing to low levels of service (particularly the near total absence of radial dual-carriageway or motorway provision) and extensive frontages in many cases, particularly in 'urban village' environments. 
13. The principal circumferential link in each city is a partial ring consisting of a motorway (or largely grade-separated divided road) encircling the landward side of the city. Edinburgh's A720 is essentially complete, but final completion of Dublin's M50 is still around five years away. No complete outer ring exists in either city, mainly for environmental and topographical reasons. The general dearth of circumferential routes in both cities reflects a combination of natural obstacles (the coastlines, Dublin's Phoenix Park, Edinburgh's hills) and environmental problems in the available corridors. The rail networks are predominantly radial, with some circumferential (primarily freight) links; apart from Dublin's coastal DART (Dublin Area Rapid Transit) route, they are of relatively little use for trips within the built-up area.

14. The layouts of the CBDs tend to exacerbate traffic congestion. In both cases, north south movement is especially difficult, due to the east-west barriers formed by the Liffey in Dublin and the Nor' Loch Valley (Princes Street Gardens) in Edinburgh. The functions of the CBDs are divided more or less evenly north and south of the barriers. The cities possess several 'pinch points' where east-west and north- south traffic conflict. In both, east-west capacity exceeds north-south. No complete purpose-built inner ring exists in Dublin, but there is a designated inner ring route to distribute traffic around the CBD. This route is a mixture of existing wide undivided roads, roads widened to dual carriageway standard, and paired oneway streets. Similarly, Edinburgh does not possess an inner ring as such, though the JATES study ${ }^{5}$ left the possibility open (utilizing existing streets with junction improvements) for long-term traffic management purposes. Historic (pre-motor vehicle) underdevelopment of the cities' central street networks was probably due to the presence of physical barriers (e .g. Trinity College and Dublin Castle in Dublin, Calton Hill and Princes Street Gardens in Edinburgh). The later failure to develop extensive urban road networks was more a function of political and environmental problems.

15. Both cities suffer extensive congestion problems, exacerbated by rising car ownership and employment growth in both inner and peripheral zones. Modal split for peak trips to the CBD in the 1990s was in the region of 59:41 in favour of public transport in Edinburgh (slow modes excluded). ${ }^{5}$ In Dublin, with slow modes included, cars accounted for $50 \%$ of such trips. ${ }^{6}$ In the mid1990s, mixed-traffic bus speeds were around $15 \mathrm{~km} / \mathrm{h}$ in Edinburgh and $20 \mathrm{~km} / \mathrm{h}$ in Dublin.7 Peak spreading appears to have taken place on a large scale over the past decade in both cities; transport problems are furthermore giving rise to serious air quality problems.

\section{Transport planning in Dublin and Edinburgh}

16. An extensive review of published literature was carried out for the purposes of this paper, an overview of which is presented in Table 2 . The late 1980s saw increased transport planning activity in both cities with particular attention given to public transport and the potential of LRT. Edinburgh, following the cancellation of the contentious Western Approach Road, had instituted an investigation of public transport options- the Edinburgh Area Public Transport Study (EAPTS). ${ }^{8}$ This study reported in 1989, favouring a 'light metro' system (LRT with a short underground section). A strategic study- Joint Authorities Transport and Environmental Study (JATES) - $^{5}$ followed in 1990-91, motivated partly by the need to demonstrate the rail scheme's merits for funding purposes and partly by increasing congestion levels and other transport-related problems. 
17. A strategic model for the city and surrounding area was developed; features included a coarser zone structure than its predecessors, inclusion of supply-side characteristics with iteration to balance supply and demand, and a simplified network structure. A range of environmental, socio-economic and transport indicators, including speeds, accident levels, fuel consumption, accessibility and economic development impacts, was used. The model is described in detail by May et al ${ }^{9}$. JATES did not recommend a single strategy, but identified the relative merits of a range of strategies drawn from various combinations of better-performing elements from initial 'theme strategies'; these elements included LRT, road pricing and capacity reduction.

18. Since the final report of JATES (mid-1991) the city has prioritized shorter-term projects, with political and funding problems causing suspension of LRT development. Progress has been made on bus priorities and environmental improvements. Innovative proposals were recently put forward for road pricing combined with hypothecation to finance public transport measures. Part of the former east- west LRT proposal is currently planned for implementation as a guided busway, the City of Edinburgh Rapid Transit (CERT). Plans for a Scottish Parliament have intensified concerns over the present traffic situation, with serious fears expressed over the impact of the traffic generated on an already severely constrained CBD.

Table 2. Overview of transport planning in Dublin and Edinburgh

\begin{tabular}{|c|c|c|c|}
\hline Study type & $\begin{array}{l}\text { Methodological/general } \\
\text { characteristics }\end{array}$ & Dublin & Edinburgh \\
\hline $\begin{array}{l}\text { General traffic study (1940s- } \\
1960 \text { s) }\end{array}$ & $\begin{array}{l}\text { Introduction of O-D data; } \\
\text { extensive road proposals }\end{array}$ & Schaechterle $(1961-68)^{18,19}$ & $\begin{array}{l}\text { Abercrombie and Plumstead } \\
(1949)^{20}\end{array}$ \\
\hline $\begin{array}{l}\text { Land-use and transportation } \\
\text { study (1960s-1970s) }\end{array}$ & $\begin{array}{l}\text { Computer modelling; } \\
\text { consideration of land-use } \\
\text { strategy; road-dominated } \\
\text { transport strategy; increased } \\
\text { traffic restraint }\end{array}$ & $\begin{array}{l}\text { Dublin Transportation Study } \\
\text { (DTS) (1969-72) }\end{array}$ & $\begin{array}{l}\text { City of Edinburgh Planning and } \\
\text { Transport Study (1968-72) }\end{array}$ \\
\hline Rail study (1970s) & $\begin{array}{l}\text { Based on previous LUTS with } \\
\text { some refinements; wide range of } \\
\text { systems considered }\end{array}$ & $\begin{array}{l}\text { Dublin Rail Rapid Transit Study } \\
(1973-75)\end{array}$ & $\begin{array}{l}\text { Review of Public Transport } \\
\text { Elements (1974-75) }\end{array}$ \\
\hline Consultative process (1970s) & $\begin{array}{l}\text { Driven by public opinion; little } \\
\text { modelling }\end{array}$ & $\begin{array}{l}\text { Transport Consultative } \\
\text { Commission }(1978-80)^{21}\end{array}$ & 'Green Papers' $(1975-79)^{22,23}$ \\
\hline Public transport studies (1980s) & $\begin{array}{l}\text { Central role for LRT; buses as } \\
\text { principal alternative }\end{array}$ & LRT feasibility studies, $1988-90$ & $\begin{array}{l}\text { Edinburgh Area Public } \\
\text { Transport Study (1987-89) }\end{array}$ \\
\hline Strategic studies (1990s) & $\begin{array}{l}\text { Coarse zone structures; denand/ } \\
\text { supply equilibration; land-use } \\
\text { sensitivity testing }\end{array}$ & $\begin{array}{l}\text { Dublin Transportation Study/ } \\
\text { Initiative }(1990-94)^{10}\end{array}$ & $\begin{array}{l}\text { Joint Authorities Transport// } \\
\text { Environmental Study (1989-91) }\end{array}$ \\
\hline
\end{tabular}

19. A variety of factors induced Dublin to undertake a strategic study at around the same time as Edinburgh. Among them were the availability of European funding, changes in government policy and the increasing irrelevance of 1970s studies and their recommendations. The strategic study Dublin Transportation Initiative (DTI) ${ }^{10}$ - was, in general methodology, very similar to JATES. The most notable technical difference was the availability of a finer zoning system for certain purposes. However, the overall study differed markedly in pursuing a single recommended strategy, rather than the variety of indicative strategies proposed by JATES. 
20. Since the DTI strategy was finalized in 1994 (Figs 1 and 2), progress has been slow on its major capital elements, notably an LRT network and a road tunnel linking the M50 to the port, both only now reaching public inquiry stage. In mid-1998, a significant redesign of the LRT system took place, the first phase being expanded to incorporate two separate (one surface, one underground) lines through the CBD, closely resembling Edinburgh's 1989 plans. This followed a study of underground options, ${ }^{11}$ based on the original first phase, which had ultimately favoured surface construction.

21. Examination of the merits of 'light metro' in Dublin was one result of unprecedented economic and demand growth, far out-stripping DTI projections. Interim measures, including bus priority and heavy rail improvements, have thereby gained impetus. Road pricing, only briefly mentioned by DTI, is now the subject of a scoping study.

\section{Review}

\section{General comparison}

22. It is clear that the general courses followed by transport planning in Dublin and Edinburgh since 1957 have been similar in timing, methodology and, in many cases, conclusions. It would be unrealistic to attribute this solely to the cities' physical or functional resemblances, since many significant events fit a more general pattern of British and Irish urban transport trends. Steer ${ }^{12}$ identifies JA TES as part of a pattern of 'integrated transportation studies' carried out in the UK during the early 1990s. Other areas undertaking similar studies included Birmingham, Leeds, Avon and Humberside. The DTI's timing and general characteristics (vision statement, appraisal methodology and medium- to long-term focus) also clearly fit this pattern. The previous (1970s) generation of studies are identified as 'land-use transportation studies' (LUTS). In timing and methodology, both the City of Edinburgh Planning and Transport Study ${ }^{13}$ and the (1970s) Dublin Transportation Study (CEPTS) ${ }^{14}$ are relatively close fits with Steer's LUTS archetype. Therefore, the similarities of these landmark studies are considered to be products of trends rather than local factors. 


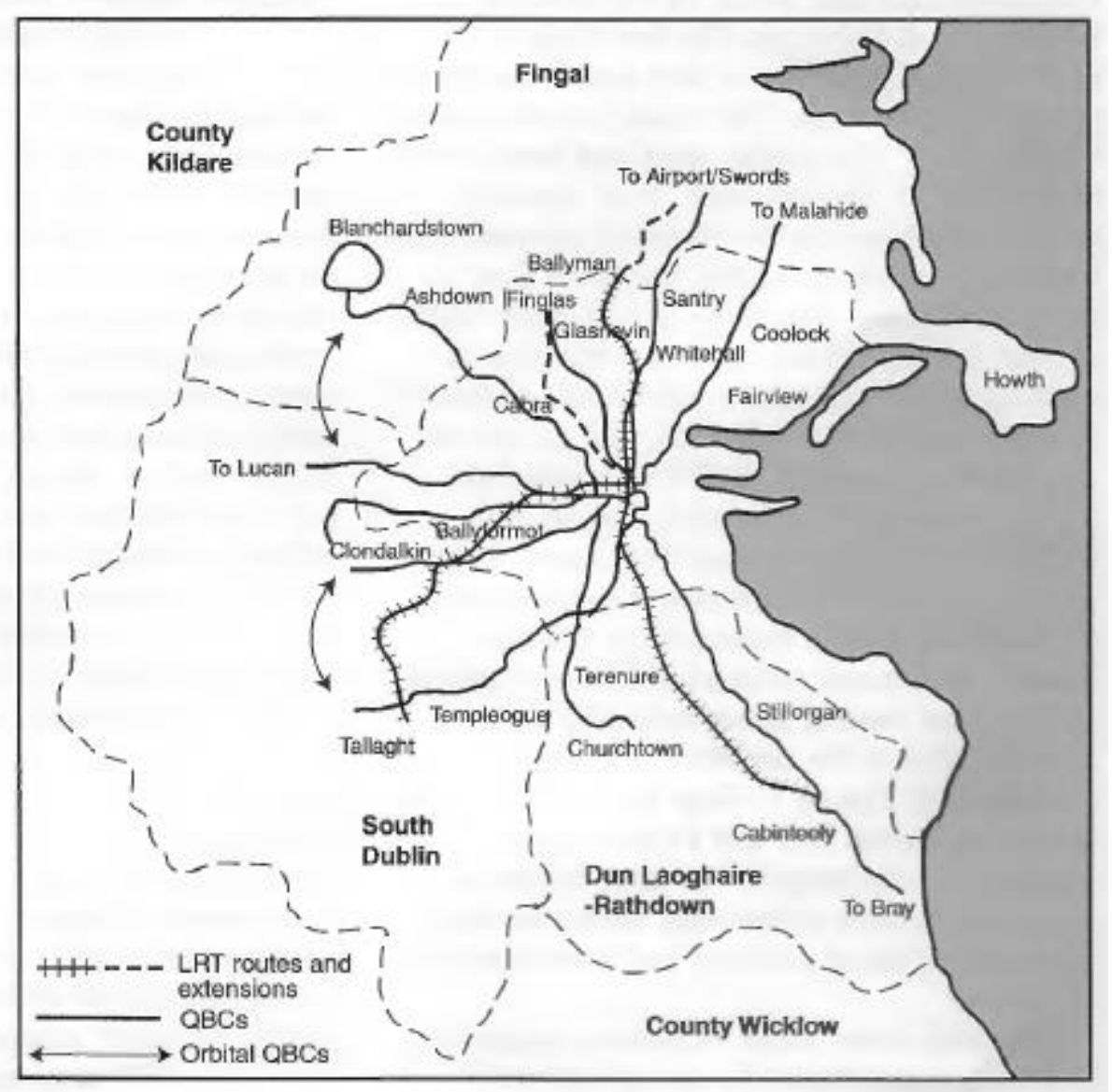

Fig 1. Main DTI public transport proposals ${ }^{10}$

23. Other clear parallels emerge, as set out in Table 2. The most important of these is between the two 1975 rail studies. ${ }^{15,16}$ In addition to their timing, they shared an origin in general studies which were, paradoxically, somewhat unfavourable to rail. Dublin's study was recommended by the DTS; Edinburgh's appears to have resulted from lobbying. External factors (the 1973 OPEC oil crisis and a trend towards urban rail at the time) were significant influences.

24. It may be concluded that the parallels in overall planning do not result from any similarity in form or function, but rather a combination of external events, political climate and transport planning 'best practice'. However, it has been established that parallels do exist in the general course of transport planning. It is possible to compare the cities on an issue by issue basis. Table 1 offers some examples of factors affecting the cities' decisions on transport issues, with particular reference to light rail and bus priorities.

25. It will be observed that the population densities on transport corridors proposed for a particular mode are (allowing for variations in the form of the basic data) generally similar between the cities. However, there is no readily discernible difference in the density range of areas along bus and LRT corridors in Dublin. (Total corridor populations may well be higher for LRT than bus in both cases.) This suggests problems of LRT network coverage in Dublin, possibly reflecting financial constraints or the prioritization of access to specific areas. Technical influences appear generally similar in both 
cases; an important socio-economic difference is LRT's greater role in Dublin's urban renewal strategies.

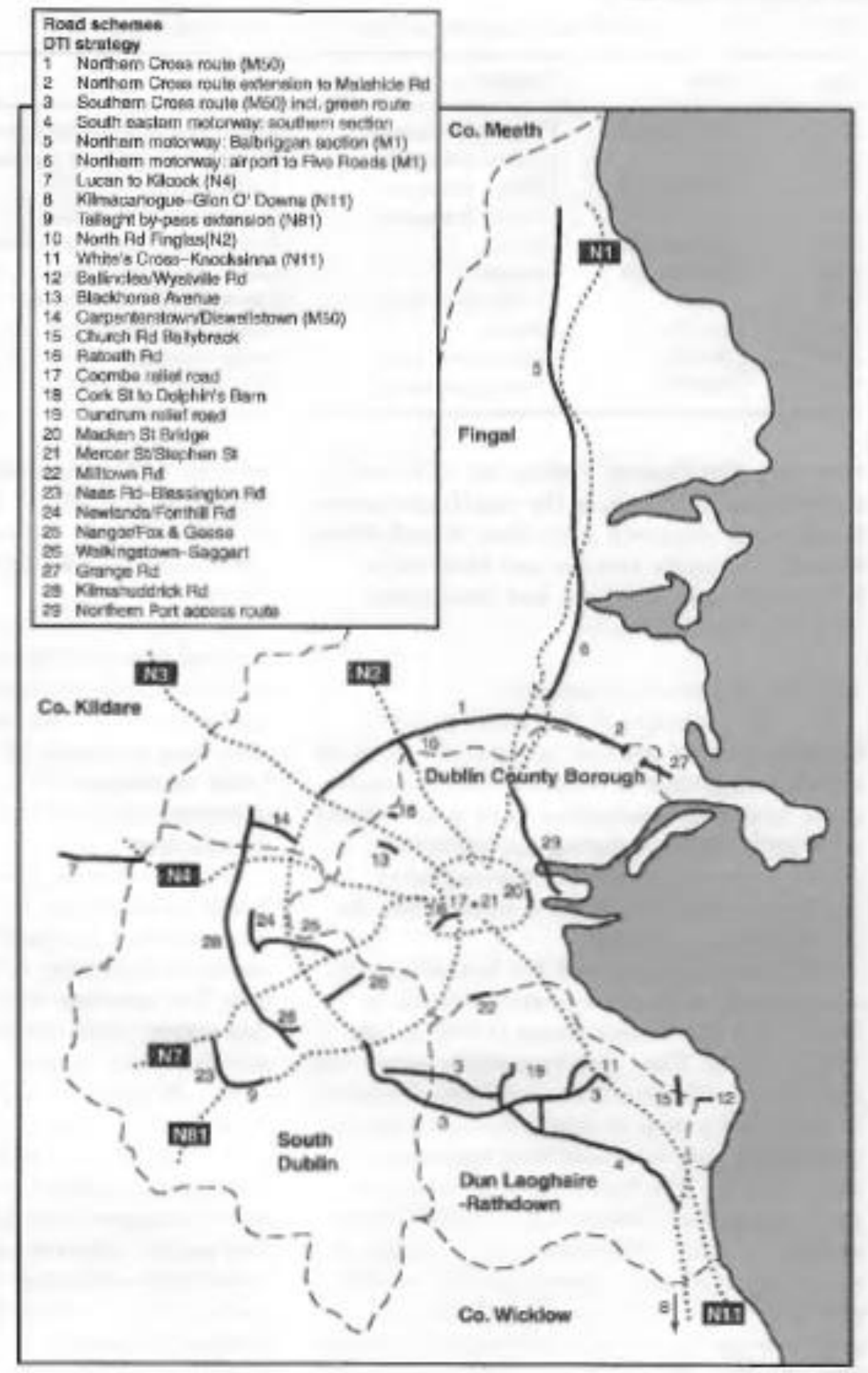

Fig 2. Main DTI Road Proposals ${ }^{10}$ 
Politics, the public and transport planning

26. A factor that emerged to a large degree in the literature review was the political influence on numerous key decisions. This often involved conflict with technical advice or alternatively the decision to cancel or resurrect a project favoured or opposed by the political opposition. Table 3 summarizes some major decisions in both cities considered, on the basis of these criteria, to be politically influenced. Although such influences are not specific to these cities, they have apparently been particularly prominent in them.

27. A further factor emerging from Table 3 is the greater influence exerted by central government in Dublin as opposed to Edinburgh, reflecting Dublin's dominance over the state and the centralization of the Irish governmental structure. Not directly visible, but reflected in many of the decisions, is the significant (exceptional when compared with other British cities) influence of public opinion and lobbying in Edinburgh over the years, and their recent growing effect in Dublin.

What are the areas of contrast?

28. The objective of this exercise is to identify areas of contrast between the cities in question, and thus to examine them in greater detail to enable conclusions to be drawn. Many such areas emerged during the literature review; only a few could be the subject of detailed comparison. Table 4 summarizes the main points of contrast.

29. The issues selected for further consideration tend to relate to current debates in Dublin and thus reflect recent (1990s or late 1980s) events. They also necessarily reflect the availability of information and their relevance to the cities' points of similarity. For example, port access was not considered appropriate, given Edinburgh's lesser role as a port compared to Dublin. Concentration on LRT at the expense of heavy rail reflects the fact that, inrecent years at least, neither city has considered heavy rail (with its cost and flexibility problems) as the core of a future public transport strategy. However, heavy rail improvements are important in the present short term strategies of both cities.

Table 3. Political decisions and transport in Dublin and Edinborgh

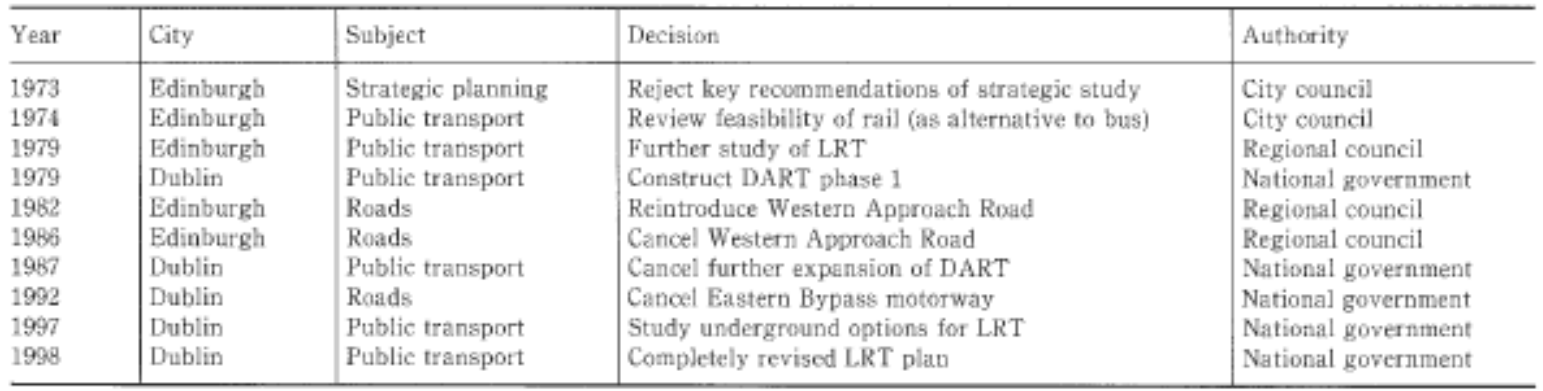




\section{Examination of key issues}

\section{Light rail issues}

30. The first issue relating to LRT to be examined was the most fundamental- that of whether LRT or bus offered greatest overall advantage to a city of this size. Particular regard was made to the contrast between the current Dublin LRT and Edinburgh busway schemes.

31. The busway concept in Edinburgh resulted from JATES' suggestions to the effect that a highquality, high-capacity (probably guided) busway could be implemented on an east-west alignment at a lower cost than LRT. Other advantages claimed at the time included collector- distributor efficiency and incremental development.

32. By contrast, Dublin's (DTI) decision ${ }^{10}$ firmly favoured rail for the busiest corridors, with on street bus priorities elsewhere. Guided busways apparently received some consideration. The principal arguments against bus in this respect were capacity, speed, image and environmental impact.

33. Meaningful conclusions are difficult to draw from this aspect of comparison, partly due to the limited information available on busways (particularly guided) worldwide, owing to their rarity compared with LRT. It was established that guided busways could overcome certain objections to the mode raised in DTI, but also that CERT did not exhibit all the advantages habitually claimed for busways. Availability of funding emerged as the most important factor in the bus/rail choice. Table 1 illustrates some other factors; they do not exhibit any conclusive pattern, other than a correlation- in Edinburgh, at least- between higher-demand corridors and rail systems.

34. Another fundamental factor was the infrastructure type chosen for city centre LRT operation. Dublin's LRT proposals were origin- ally (until May 1998) characterized by entirely on-street operation in the city centre. By comparison, Edinburgh's 1989-91 'Metro' proposals involved two distinct city centre routes, one mainly surface and the other underground.

35. Factors affecting decisions on infrastructure type were compared; not all were common to both cities, but it was nevertheless possible to shed some light on the Dublin debate. The EAPTS ${ }^{8}$ favoured tunnelling principally because of the likely negative effects of traffic diversion and servicing restrictions for a surface priority corridor on a similar alignment (natural constraints and poor ring roads cannot have helped). Public opinion also appears to have been a significant factor, particularly in a subsequent extension of the proposed tunnel. Traffic diversion was among the effects which Dublin's recent study ${ }^{11}$ identified as contributing to surface operation's negative traffic impacts and in turn to its lower economic benefits (though still being considered superior overall, due principally to lower capital cost). Site-specifics, particularly the existing tunnel on part of Edinburgh's underground alignment, appear important, though not so much as to invalidate comparisons (Table 1). Considering the similarity in form between the cities and the relevance to constraints on road space, the 'light metro' could be considered a logical, although costly, option for study in the Dublin context. 


\begin{tabular}{l|l|l} 
Teble 4. Principal areas of contrast & & Cotzidered in detail? \\
\hline Aspect & Contrast & Yes \\
\hline LRT (design) & Tunnel sections in Edinburgh but not (originally) Dublin & Yes \\
Public consultation & Public offered choice between conplete strategies in Edinburgh, not in Dublin & No \\
Slow modes & Greater/earlier attention to cycling in Edinburgh & Yez \\
Strategic studies & Choice offered to implementers by JATES, not DTI & Yes \\
Bus versus rail & Initial rapid transit line to be rail in Dublin, busway in Edinburgh & Xv \\
1970s LUTS & Public consultation in Edinburgh, not Dublin & \\
\hline
\end{tabular}

Choice and public consultation issues

36. Edinburgh, due possibly to its longer tradition of conservationism and high levels of activism, ${ }^{4}$ has generally attached more importance to consultation than Dublin; this is changing as Dublin's processes (and opponents' strategies) become better developed. Edinburgh's EAPTS/JATES/Metro processes were compared with Dublin's DTI/LRT processes; the main contrasts are presented in the following paragraphs.

37. The most significant difference was the EAPTS proposal of four 'option networks' for consultation, allowing the public to choose their

- preferred network, in parallel with a comparative technical evaluation. DTI did not adopt this approach. Although opinions on various

- strategy elements were sought at one stage, no choice as such was offered. Only one strategy appears to have been offered to the public at any time, although a consultative panel representing a wide range of groups was consulted on an ongoing basis throughout the DTI process.

38. The DTI strategy (Figs 1 and 2) is commonly referred to as a 'seamless garment'; that is, elements cannot be implemented in isolation, and 'popular' elements cannot be effective without 'unpopular' ones. Transport planning is thus rendered predictable but not especially flexible. JATES (not entirely uniquely in Britain) $)^{12}$ adopted the approach of demonstrating the performance of a range of combinations from a set of worthwhile elements, the ultimate choice being left to the implementers. Such flexibility can be valuable in situations where public resistance to certain elements, politically motivated changes of plan, altered economic circumstances and variations in funding levels are likely. It is noted that all have occurred in Dublin in recent years. Given these circumstances, there might be advantages for Dublin in adopting a philosophy offering greater choice in both consultation and implementation for future studies. It is accepted, of course, that public resistance is a common feature in many cities when unpopular plans are implemented.

Road pricing issues

39. Edinburgh has apparently been more enthusiastic about road pricing;- than Dublin, as exemplified by the JATES ${ }^{5}$ and DTI $^{10}$ studies; it was 'the key policy issue' for the former, but the latter regarded it more as an option of last resort, favouring parking control in its final strategy. With the close similarities between the two cities' problems, there is logic in reconsidering the potential of road pricing in Dublin. Indeed, such a study has recently commenced. 
40. The differing attitudes towards road pricing may be explained in part by the methodological differences of the studies. In JATES, a range of indicative strategies, allowing complete strategies with and without road pricing to be directly compared, was examined, whereas road pricing was represented only by an initial theme strategy in DTI.

41. As with the issue of underground LRT, urban form and constraints affect the feasibility and desirability of road pricing. Given the cities' similarities in these areas and Dublin's present problems, the general thrust of the JATES conclusions on road pricing could be useful in the Dublin context. The significant volume of work carried out on road pricing in Edinburgh has relevance to all cities in this size range. The measure may be of definite interest to Dublin, subject to the concerns which JATES expressed, for example the necessity of hypothecation.

\section{Conclusions}

42. The following conclusions do not represent the opinions of anybody actively involved in transport planning in either city. They merely summarize the authors' view of the available evidence.

(a) The level of funding available emerged as the primary factor influencing a choice between LRT and busway, at least on major corridors. Examination of other factors was inconclusive.

(b) On the basis of the factors affecting the feasibility of surface LRT systems in both cities, there are sufficient similarities to conclude that there was value in examining an underground alternative for Dublin.

(c) Studies offering a choice of strategy to the implementers and/or the public appear from Edinburgh's experience to be more flexible and more likely to gain public support.

(d) Road pricing, on the basis of the findings of JATES, Edinburgh and Dublin's similarities, and the latter's current problems, may be a useful measure for Dublin, provided that car users are offered feasible alternatives, yet to be realized.

(e) Several aspects of transport planning in Edinburgh are of relevance to Dublin, as shown by the comparison and contrasts made in this paper.

\section{References}

1. WHITNEY W.]. Transportation Planning in Dublin and Edinburgh 1957- 1997. Thesis, Department of Civil, Structural and Environmental Engineering, Trinity College, Dublin, 1998.

2. CENTRAL STATISTICS OFFICE. Census 96 Preliminary Report. Stationery Office, Dublin, 1997.

3. GENERAL REGISTER OFFICE. 1991 Census. HMSO, Edinburgh, 1993. 
4. HAGUE C. The Development of Planning Thought. Hutchinson, London, 1984.

5. MVA CONSULTANCY. Joint Authorities Transport and Environmental Study: Strategies Study: Final Report. Unpublished, 1991.

6. STEER DAVIES GLEAVE. Dublin Transportation Study Phase 1. Stationery Office, Dublin, 1991.

7. ]ANE'S INFORMATION GROUP. Jane's Urban Trans" port Systems 1998-99. Jane's, London, 1998.

8. LOTHIAN REGIONAL COUNCIL. Edinburgh Area Public Transport Study. Unpublished, 1987 89, (4 vols).

9. MAY A. D., ROBERTS M. and MASON P. The development of transport strategies for Edinburgh. Proceedings of the Institution of Civil Engineers Transport, 1992, 95, Feb., 51-59.

10. DUBLIN TRANSPORTATION INITIATIVE, STEER DAVIES GLEAVE, McHUGH CONSULTANTS. Dublin Transportation Initiative: Final Report. Stationery Office, Dublin, 1995.

11. WS ATKINS. Dublin Light Rail: Comparative Assessment of Surface and Underground Options: Final Report. WS Atkins, Epsom, 1998.

12. STEER ]. The formulation of transport policies in British conurbations, 1990-1995. Proceedings of the Institution of Civil Engineers Transport, 1995, 111, Aug., 198- 204.

13. COLIN BUCHANAN AND PARTNERS, FREEMAN FOX AND ASSOCIATES, EDINBURGH CORPORATION. City of Edinburgh Planning and Transport Study. Colin Buchanan and Partners, Edinburgh, 1971- 72 (3 vols).

14. AN FORAS FORBARTHA. Transportation in Dublin. An Foras Forbartha, Dublin, 1971.

15. ALAN M. VOORHEES AND ASSOCIATES. Dublin Rail Rapid Transit Study. CIE, Dublin, 1975.

16. DE LEUW CHADWICK O HEOCHA. Edinburgh: A Review of the Public Transport Elements of the Recommended Plan. De Leuw Chadwick O'hEocha, Edinburgh, 1975.

17. FEE]. M. Land Use Along the Proposed Dublin Light Rail Transit Corridors. MSc thesis, Depart• ment of Civil, Structural and Environmental Engineering, Trinity College, Dublin, 1994.

18. SCHAECHTERLE K. Dublin General Traffic Plan. Ulm·Donau, 1965-69 (2 vols).

19. SCHAECHTERLE K. A Plan for Dublin 's Bus Ser"vices. Ulm·Donau, 1969. 
20. ABERCROMBIE P. and PLUMSTEAD D. Civic Survey and Plan for the City and Royal Burgh of Edinburgh. Oliver and Boyd, Edinburgh, 1949.

21. TRANSPORT CONSULTATIVE COMMISSION. Passenger Transport Services in the Dublin Area. Stationery Office, Dublin, 1980.

22. LOTHIAN REGIONAL COUNCIL. The Development of Transportation Policy: Edinburgh Area: A Paper for Discussion. The Council, Edinburgh, 1977.

23. LOTHIAN REGIONAL COUNCIL. Transportation in the Edinburgh Area. The Council, Edinburgh, 1979. 